\title{
Topically applied heparin in venous thrombosis, why not using it: A review of literature
}

\author{
Khaled Assim Karkout* \\ Department of General Surgery, Division of Surgical Oncology, Tawam hospital Al Ain, United Arab Emirates
}

\begin{abstract}
Superficial vein thrombosis (SVT) is a condition of clotting of superficial veins associated with minimal inflammatory components, while superficial thrombophlebitis (STP) is defined as a condition of minimal thrombosis of superficial veins associated with inflammation or infection. In UK it is estimated to have 400 cases of SVT in every 100000 person per year in comparison to 125000 case annually in the United States. SVT and STP tend to occur more in old ages because of increased incidence of varicose veins, with a tendency toward working population. Women are affected more in the UK, but the San-Valantino study showed a similar rate. Obese low mobility people, pregnant ladies, females on contraceptives and hormone replacement therapy (HRT) are more affected by the two conditions. Conventional treatment of both conditions is conservative and usually includes pain killers, compression, anti-inflammatory creams and elevation. Anticoagulation is indicated in some cases, whether systemic or topical. SVT and STP are better prevented than treated, and some simple steps help to achieve that goal. Removal of intravenous (IV) catheters after maximum 48 hours of usage and avoidance of small veins while puncturing are some but not all. Low molecular weight heparin (LMWH) and nitroglycerin patches distal to peripheral lines can also prevent SVT and STP. Exercise is recommended while total bed rest is not in such cases. Antibiotics are usually conserved for cases with proved source of infection.
\end{abstract}

Our main concern in this paper is to review the literature regarding the use of topical heparins in SVT and STP. Although it was mentioned in many trials and expert opinions, the use of topical heparin is not yet standardized and its use is limited to some centers only. It still lacks the enough evidence because of deficiency in large pharmaceutical investments in this field, yet it has shown many beneficial effects in clinical practice. Scientifically speaking, three main effects of heparin on skin can be observed; a)the anti-coagulation effect, b)modulatory effect on microcirculation, c)the effect on skin permeability allowing increased diffusion of drugs [1-3].

\section{Discussion}

One double blinded randomized controlled study (RCT), concluded that the application of topical $1000 \mathrm{IU}$.g1 is an effective treatment for superficial thrombophlebitis caused by IV catheters. The study has proven that topical heparin hastens the healing process, which decreases the comfort caused by phlebitis, especially in patients with more than one lesion who needs a new catheter to be inserted. In this study diagnosis of phlebitis was made by 10 nurses, and the course progression by 19 [4]. A Research by Angiology suggested that topical heparin can effectively modulates the microcirculations and increase diffusion throughout the skin. Those proposed actions were noticed in patients with chronic venous hypertension, diabetic microangiopathy, peripheral vascular disease, and vascular ulcerations. It was found that both heparin factors e.g. Concentration, formulation, $\mathrm{PH}$, etc. and skin factors e.g. Temperature and humidity play an important role in the process. The study showed that in non-complicated cases of superficial thrombophlebitis a topically applied heparin formula may positively influence skin microcirculation by reducing vasodilation caused by vasopeptides release which is responsible for signs of inflammation. It may also decrease local thrombogenecity and hence the recurrence, and in addition it may improve the spontaneous lysis of the local thrombosis. It was found that reduction in thrombus size in patients with locally applied heparin occurred 3 times faster than other patients after two weeks.the heparin used in the research was, liposomal spraygel heparin [5]. Another RCT study published showed that the use of Essavin Gel (contains aescin, heparin and essential phospholipids); on a skin with venous hypertensive microangiopathy improves the local microcirculation. There for it is advised to apply this treatment in order to improve healing, and prevent ulceration [6,7]. It was found that daily treatment with Essavin Gel in diabetic microangiopathy may be beneficial to prevent ulcrearation, control DM, and improve healing of diabetic ulcers [8]. An expert opinion document published in 2003 [9], indicated that spray application of heparin on SVT reduces skin redness, and decreases thrombus size, especially if combined with compressive stocking.

An RCT published in 2003 claimed that local application of heparin had an efficacy comparable to LMWH [10]. In 2003, and 2005 two studies of the same design $[11,12]$ concluded that LMWH is equally effective in comparison with topically applied heparin regarding the reduction of erythema, swelling and pain. Another study [13], compared LMWH with topically applied heparin in alleviating the above mentioned symptoms. In this study it was concluded that pain relief in the group which received topical heparin was better achieved than the control group. Reduction of other inflammatory symptoms (redness and swelling) was more remarkably obvious. Moreover the reduction in the thrombus size after two weeks of treatment was three times bigger in the group which used topical heparin.

*Correspondence to: Khaled Assim Karkout, Department of General Surgery, Division of Surgical Oncology, Tawam hospital Al Ain, United Arab Emirates

Key words: Superficial vein thrombosis, superficial thrombophlebitis, Low molecular weight heparin, nitroglycerin

Received: March 30, 2018; Accepted: April 16, 2018; Published: April 18, 2018 


\section{Conclusion}

Topically applied heparin has shown a promising role in treatment of SVT and STP. Recent literature has shown its effectiveness in the reduction of inflammatory sign accompanying those conditions. However there is still no enough evidence supporting the role of locally applied heparin in prevention of complications e.g. deep venous thrombosis, pulmonary embolism as compared to LMWH.

Neverthless, many institutes have included topically applied heparin in their guidelines for treatment of SVT and STP, and so far they have increased the patients' satisfaction for faster pain relief, which is the main disturbing element of those diseases.

\section{References}

1. Parisel C, Saffar L, Gattegno L, André V, Abdul-Malak N, et al. (2003) Interactions of heparin with human skin cells: binding, location, and transdermal penetration. $J$ Biomed Mater Res A 67: 517-523. [Crossref]

2. Szczesny G, Veihelmann A, Nolte D, Olszewski WL, Messmer K (2001) Heparin protects local skin microcirculation in 210 minutes-long intravital microscopy observations under general anaesthesia. Eur J Med Res 6: 175-180. [Crossref]

3. Cesarone MR, Belcaro B, Errichi S, Cornelli U, Pellegrini L, et al. (2007) Topical Heparin: New Observations. Angiology 58: 1S.

4. Vilardell M, Sabat D, Arnaiz JA, Bleda MJ, Castel JM, et al. (1999) Topical heparin for the treatment of acute superficial phlebitis secondary to indwelling intravenous catheter.A double-blind, randomized, placebo-controlled trial. Eur J Clin Pharmacol 54: 917-921. [Crossref]
5. Cesarone MR1, Belcaro G, Corsi M, Ippolito E, Errichi S, et al. (2007) Local heparin, superficial vein thrombosis. Angiology 58: 36S-40S. [Crossref]

6. De Sanctis MT, Incandela L, Belcaro G, Cesarone MR (2001) Topical Treatment of Venous Microangiopathy in Patients with Venous Ulceration with Essaven Gel: A Placebo-Controlled, Randomized Study. Angiology 52: S29-S34. [Crossref]

7. Arslanagic I, Brkic N (1982) Our experience in the treatment of acute sport injuries with Essaven gel. Med Arch 35: 205-208.

8. Incandela L, Belcaro G, Cesarone MR, De Sanctis MT, Griffin M (2001) Microvascular alterations in diabetic microangiopathy: topical treatment with Essaven gel-a placebocontrolled, randomized study. Angiology 52: S35-S41. [Crossref]

9. Cesarone MR, Belcaro G, Agus G, Georgiev M, Errichi BM, et al. (2007) Management of Superficial Vein Thrombosis and Thrombophlebitis: Status and Expert Opinion. Angiology 58: 7S-14S. [Crossref]

10. Katzenschlager R, Ugurluoglu A, Minar E, Hirschl M (2003) Liposomal heparinspraygel in comparison with subcutaneous low molecular weight heparin in patients with superficial venous thrombosis: a randomized, controlled, open multicentre study. J Kardiol 10: 1-4.

11. Katzenschlager R, Hirschl M, Minar E, Ugurluoglu A (2003) Liposomal heparinspraygel in comparison with subcutaneous low molecular weight heparin in patients with superficial venous thrombosis. A randomized, controlled, open multicentre study. J Kardiol 10: 375-378.

12. Gorski G, Szopinski P, Michalak J, Marianowska A, Borkowski M, et al. (2005) Liposomal heparin spray: a new formula in adjunctive treatment of superficial venous thrombosis. Angiology 56: 9-17. [Crossref]

13. Katzenschlager R, Ugurlouglu A, Sipos G, Bihari I, Anyova EB, et al. (2007) Efficacy and Tolerability of Liposomal Heparin Spraygel as an Add-on Treatment in the Management of Superficial Venous Thrombosis. Angiology 58: 27S-35S. [Crossref]

Copyright: $@ 2018$ Karkout KA. This is an open-access article distributed under the terms of the Creative Commons Attribution License, which permits unrestricted use, distribution, and reproduction in any medium, provided the original author and source are credited. 